CIC. Cuadernos de Información y Comunicación

ISSN: $1135-7991$

http://dx.doi.org/10.5209/ciyc.69350

\title{
De Peirce en Castañares: Paideia y Agapismo ${ }^{1}$
}

\author{
Gonzalo Abril ${ }^{2}$
}

Enviado: 10 de marzo de 2020 / Aceptado: 10 de mayo de 2020

Resumen. Texto en homenaje a la figura y a la obra de Wenceslao Castañares, en el que se reflexiona con profundidad sobre los conceptos y las actitudes del profesor citado, señalando cómo su ejercicio de la docencia y la investigación era acorde con algunos de los más fecundos ideales de Charles Peirce, en los que se unía muy estrechamente la teoría y la praxis de la comunicación y el conocimiento.

Palabras Clave: Wenceslao Castañares, Charles Sanders Peirce, semiosis, agapismo, comunidad de investigadores, cuasimente.

\section{[en] From Peirce in Castañares: Paideia and Agapism}

Abstract. This text is a homage to the figure and the work of Wenceslao Castañares, reflects in depth on the concepts and attitudes of the aforementioned professor, pointing out how his practice of teaching and research was in accordance with some of the most fertile ideals of Charles Peirce, in which the theory and praxis of communication and knowledge were very closely linked.

Keywords: Wenceslao Castañares, Charles Sanders Peirce, semiosis, agapism, community of researchers, quasi-mind.

Cómo citar: Abril, G. (2020). De Peirce en Castañares: Paideia y Agapismo, en CIC. Cuadernos de Información y Comunicación 25, 17-21.

En la introducción al Tratado de la naturaleza humana escribió el filósofo David Hume: "La victoria no es ganada por los hombre de armas, que manejan la pica y la espada, sino por los trompeteros, tamborileros y músicos de la armada". Con esta alegoría castrense el filósofo escocés lamentaba sarcásticamente, como ha hecho siempre la gente del mundo intelectual y académico, el éxito que conocen los colegas más oportunistas y frívolos y el agravio comparativo que pesa sobre quienes contemporáneamente realizan un trabajo austero, comprometido, a menudo intempestivo (tal como caracteriza Agamben el pensamiento verdaderamente "contemporáneo") y por ello mismo más peligroso y menos recompensado por los halagos públicos.

En la escena del pensamiento semiótico actual, la alegoría de Hume no es menos vigente de lo que podía ser en la comunidad filosófica del siglo XVIII. Con frecuencia las relaciones públicas o la astucia institucional suplantan al verdadero trabajo

1 Este texto, salvo leves modificaciones, fue leído por su autor en el acto de Homenaje a Wenceslao Castañares que se celebró en la Facultad de Ciencias de la Información el día 10 de diciembre de 2018.

2 Catedrático Emérito Universidad Complutense de Madrid.

abril@ucm.es 
investigador. A través de portales como Academia.edu accedemos también a ensayitos o microtratados que resuelven de una vez por todas la "semiótica del pixel", "la semiótica del rostro heroico" o la "semiótica del extremismo", como si la semiótica fuera el abrefácil de todas las cajas negras. En la era de Google hay muchos vivaques para los tamborileros y trompeteros de Hume. Parece que el gran filósofo ilustrado tenía en baja estima a los músicos del ejército. Pero ya se sabe que "música militar" es un oxímoron, y lo debía de ser aún más rotundamente cuando publicó su Tratado, pocos años después de que Juan Sebastian Bach hubiera estrenado La pasión según San Mateo.

Wenceslao Castañares ha sido siempre de quienes "manejan la pica y la espada". Esto es cierto en general, pero de un modo especialmente apreciable en el segundo volumen de su Historia del pensamiento semiótico, el dedicado a la filosofía medieval, que vio la luz pública pocos días antes de su terrible y prematuro fallecimiento. Escribió James Baldwin que la muerte de todo escritor o intelectual, a no ser que sea una persona muy anciana, es prematura, pues le suele sorprender ocupado vivamente en proyectos y trabajos en curso. También esta afirmación es especialmente cierta en el caso de Wenceslao, que ha dejado inacabado el proyecto de Historia del pensamiento semiótico que venía abordando durante los últimos años con la pasión y a la vez con el rigor meticuloso que le caracterizaban. Así que el "manejar la pica y la espada" no es sólo la metáfora de una dedicación y de una laboriosidad fuera de dudas. Lo es también de una pasión intelectual y de una seriedad -de la seriedad entendida como actitud moral primordial- del todo excepcionales en nuestra época.

Tuve la suerte de compartir despacho con Wenceslao durante más de diez años. Así que manteníamos conversaciones muy frecuentes sobre temas que nos interesaban a ambos. Sólo muy raramente las comidillas de la vida universitaria. Hablábamos de música y de arte, de libros filosóficos recientemente leídos, del alumnado que compartíamos, de la sofocante burocratización de la investigación y la docencia. Es bien sabido que era un gran docente. No un profesor, sino un educador, un verdadero pedagogo, tomando esta palabra en el sentido que le daba la Grecia clásica por oposición al didáscalos, el enseñante especializado en una materia particular.

En esas conversaciones me hizo comprender la labor titánica que suponía internarse en la jungla del pensamiento medieval, el más rico desde el punto de vista de la semiótica, de la lingüística y de la lógica en toda la historia del pensamiento occidental (como el propio Jakobson había reconocido en su momento), la dificultad de encontrar fuentes, de traducir del latín, de cotejar con lugares comunes y prejuicios enquistados en los manuales desde siglos atrás. Se le veía desbordado y a la vez entusiasta, pletórico de salud intelectual cuando respondía a mis preguntas sobre la exégesis medieval, sobre el cuadrado semiótico de Anselmo o las metáforas agrícolas de Hugo de San Víctor.

Pero además de la historia del pensamiento semiótico, grecolatino y medieval, Wenceslao se había interesado anteriormente, con la misma pasión y seriedad, por la televisión contemporánea, las emergentes ontologías de la virtualidad, la mímesis y la ficción, el universo mediático y la cultura de masas, la teoría de la interpretación y la lectura, un diccionario de citas...

$\mathrm{Y}$, por supuesto, central y transversalmente, por la semiótica de Peirce, campo en el que, desde su tesis doctoral, era un reputado especialista. La edición póstuma de sus Escritos sobre C. S. Peirce, a cargo de Sara Barrena y Jaime Nubiola (Pamplona, Eunsa, 2019) ofrece un merecido reconocimiento, aparte de un texto con enorme 
interés intrínseco. Y me consta que muchas personas, incluso fuera del ámbito de los estudios sobre comunicación, saben de Wenceslao Castañares ante todo como estudioso de Peirce. Esta relación con el filósofo de Massachusetts, aunque sólo haga justicia parcialmente a su obra escrita y a su labor docente, tiene algo de profundamente acertado, por las razones que voy a exponer muy brevemente.

Wenceslao no sólo conocía y apreciaba la obra de Peirce. Wenceslao era profunda y radicalmente peirceano. Si se interroga la relación del semiólogo Castañares con el semiótico norteamericano no habría de ser en términos de "Castañares (dice) sobre Peirce", sino más bien así: "De Peirce en Castañares", en un sentido análogo al título del hermoso ensayo de Eric Rohmer: De Mozart en Beethoven. Ensayo sobre la noción de profundidad en música. Yo creo que Wenceslao compartía la idea peirceana de que la estética precede fenomenológicamente a la ética y ésta a la lógica, y con ello, que la creación, el sentimiento, la sensación, el campo siempre abierto de lo posible, lo sensible y lo decible (la "frescura" de la primeridad) anteceden a la ética, a la experiencia y la acción, y éstas, a su vez, determinan los hábitos propios de la representación y del conocimiento racional. De esa concepción puede proceder el interés que en una época tuvo por la expresión de sentimientos morales como ingredientes de ciertos programas televisivos. Pero creo que esta prelación no sólo se daba en el orden de las convicciones intelectuales, sino sobre todo en el orden de su vida práctica, de sus actitudes, de su relación con los demás y con el medio académico. Por decirlo con categorías de mi amigo Andrés Davila -en el fondo también peirceanas-, en Wenceslao el trato (que es siempre personal, y siempre corre los riesgos y ofrece las gratificaciones de la inmediatez y de la cercanía), era respetuoso, discreto y amigable, y así prefiguraba el tratamiento, es decir, el modo, el método de abordar los problemas, prácticos o teóricos. A su vez este tratamiento determinaba el trata$d o$, el discurso teorético en que tales problemas podrían activarse como preguntas o como respuestas parciales, y siempre provisionales. Prudente y cauteloso en los tres momentos, no por casualidad trabajó y enseñó rigurosamente sobre metodología y métodos de investigación.

No pretendo decir que Wenceslao haya tomado a Peirce por un guru o un coach, obviamente. Seguro que coincidiría con Dominique Chateau, y conmigo, en haberse librado de caer en la marmita peirceana como Obelix en la de la poción mágica, y en servirse de Peirce más bien según el modo en que Asterix usa el mencionado brebaje: en ocasiones, según el problema y la circunstancia, conviene tragarse el contenido de un frasco peirceano (sí, como beber cognoscitivamente de los vasos conectados de las cuasimentes, y con moderación y finura de las copas de buen vino que también gustaban a Charles, a Wenceslao y supongo que a Dominique, por no hablar de mí mismo).

El interés temprano de Wenceslao por Peirce pudo estar regido, incluso inconscientemente, por las interpelaciones metafísicas y éticas del filósofo de Massachusetts, que vibraban como resonancias o armónicos de sus propias disposiciones subjetivas, de su propia manera de ser, de sentir y de actuar. Por ejemplo, por la doctrina del "agapismo" (uno de esos neologismos algo extravagantes de Peirce, que remite al ideal greco-cristiano del ágape como amor altruista, siempre atento a los demás). En términos del propio Peirce, el agapismo se refiere a un avance hacia el otro dirigido por "amor creativo", o "simpatía positiva" que brota de la "continuidad de la mente". Me temo que hoy se simplifican y se abusan estas actitudes, reduciéndolas a una "empatía" bastante bobalicona. Peirce, según sus editores, defendía con el aga- 
pismo la "tesis de que el amor o simpatía ejece una influencia real en el mundo y, de hecho, es "el gran agente evolutivo en el universo". Algo muy a tener en cuenta en una época, la nuestra, en que el odio y la antipatía plenamente desvergonzados de los poderosos contra los subalternos amenazan con toda clase de involuciones políticas y morales.

En la mesa de al lado, en nuestro despacho, he presenciado muchas veces las tutorías de Wenceslao, su infinita amabilidad con lxs estudiantes, no mera paciencia, ni tolerancia, ni paternalismo, sino simpatía solícita y cooperativa incluso ante las demandas más peregrinas. Esa disposición parecía albergar la confianza sincera en las posibilidades del otro, de su desarrollo autónomo, de su progreso intelectual y personal.

La amabilidad productiva del agapismo puede también relacionarse con otra idea muy fecunda y mucho más conocida de Peirce: la de la "comunidad de investigadores", que está en el centro mismo de la teoría epistemológica del filósofo.

Peirce pensaba que los intereses intelectuales no pueden restringirse a nuestro destino ni a nuestro horizonte personal de vida, porque, como Wenceslao decía, "sólo somos el tiempo que tenemos". Por eso, vuelvo a Peirce, nuestros intereses intelectuales y morales han de orientarse a la comunidad entera. Pero una comunidad que nada tiene de corporativo, de profesional, de sistema experto o de grupo culturalmente limitado y limitante. La comunidad ilimitada "debe extenderse a todas las razas de seres con las que podemos entrar en una relación intelectual mediata o inmediata", escribió Peirce. Ese es el horizonte de la racionalidad y del conocimiento. Porque, "para ser lógicos, los hombres no deberían ser egoístas". Esta orientación utópica y ucrónica de Peirce bordea el misticismo, sin duda. Pero nada tiene que ver con un imperativo ascético, con la abnegación o el autosacrificio. Por el contrario, puesto que tenemos sentimientos, y el de la esperanza es de los más positivos, podemos confiar "con un deseo tranquilo y alegre" en la larga duración de esa comunidad, que, nueva vuelta de tuerca en Peirce, y creo que igualmente en Castañares, es en tanto que comunidad de conocimiento también una comunidad de sentimiento.

Todo esto está muy lejos de la realidad fáctica y actual de la comunidad académica, una no-comunidad regida hoy por la competitividad, el egoísmo y las supersticiones del emprendimiento. Nuestro ecosistema académico, llamémoslo el sistema académico Bolonia, por abreviar, conspira en contra de los ideales peirceanos de Wenceslao, en contra de su práctica de la paideia, de su manera de pensar, enseñar y simplemente conversar.

Mucho antes de compartir despacho, compartimos con otras compañeras y compañeros un espacio de discusión que durante muchos años convocó en esta facultad a colegas y a estudiantes de distintas disciplinas a una conversación larga y apasionada en que todas y todos aprendimos mucho de todos y todas. En esa práctica poníamos a funcionar la commens, la mente común de que habló también Peirce, sin preocuparnos por los réditos que tal actividad pudiera rendir en términos de meritoriaje académico o de escalafón. No existía una Aneca a la que comunicar dócilmente los resultados contables de aquellas conversaciones. Con las franquicias académicas que hoy se denominan pomposamente grupos de investigación, esa clase de ágapes, de conversaciones abiertas, de pequeños falansterios intelectuales, los pocos que había, han sucumbido casi por completo. Al menos en el área de las humanidades.

Pero estoy seguro de que los ideales peirceanos, aquellos que orientaron la vida 
académica de Castañares, no han muerto. Seguro que otra generación celebrará su fiesta de resurección. Esta declaración de optimismo, que en mí reconozco forzada y voluntarista, es mi humilde manera de rendir homenaje al optimista lúcido y consecuente que fue mi amigo Wenceslao. 